\title{
The Innovative Exploration of Supervision Approaches of Open Education Teaching
}

\author{
Gang Han \\ Shanxi Radio and TV University, Baoji Branch \\ Baoji, China \\ 1327410110@qq.com
}

\begin{abstract}
The supervision of teaching plays an irreplaceable role in strengthening the management of teaching, ensuring the quality of distance teaching of open education and achieving the goals of teaching. Open education is the new approach of Chinese educational development and reflects the characteristics which are completely different from the traditional way of teaching. How to make the innovation of supervision of open education and undertake the effective implementation of teaching supervision are urgent problems to solve.
\end{abstract}

Keywords-open education; supervision approaches; execution of supervision

\section{INTRODUCTION}

On March 23rd, 2009, the Central TV University drew up basic rules of working approaches of teaching supervision in "Supervision Rules and Relations of Open Education in Radio and Television Universities (Trial)": the teaching supervision is undertaken under the leadership of the principal based on the requirements of teaching management system or documentation. The supervision experts are organized to inspect, supervise, and evaluate the teaching preparation, the implementation, management and teaching quality and put forward some advice and suggestions for guidance. The focus of supervision is the organization, management, implementation and effects of the various sessions in the teaching process of open education.

According to the field investigation and present problems of RTVU, it is not difficult to find that the supervision of teaching and education in most of the colleges and universities cannot be undertaken in depth, or the effect is not just as one wishes, because it is restrained to attending the lecture, checking the network information and demanding for rectification, which results from the over-reliance on traditional supervision mode, or constrained to such specific ways of "working norms" excessively as special supervision and supervision consultation. In this case, the supervision only provides references for superior decision rather than impact directly the teachers supervised, which loses the direct effectiveness of supervision, and to a certain extent, discourage the teacher's working enthusiasm.

The well-known management expert Chen Yian summarized the essence and the highest criterion of management in three sentences: stimulating the glory of human nature, returning to the value of life and co-creating prosperity and happiness. The subject of school management is teaching. The full utilization of the experts of teaching and management and keeping up with education and relevant works are of great importance. Open education has realized the change from being teacher-centered to student-centered, embodied the shift of teachers' role from teaching to helping and guiding, however, the teachers' sense of responsibility and achievement are still the real power for the improvement of distance teaching quality in open education. In view of this, the supervision of remote teaching must have people-oriented management philosophy as the standard to respect, cultivate, inspire, develop and perfect people as the starting point of school management. We should take monitoring as the means, improving teaching levels as goals, combine supervision with guiding to guarantee the quality of education fundamentally.

Teaching supervision is the generic terms of a series of activities such as supervision, inspection, control, evaluation and guidance of teaching quality. The author thinks that the innovation of supervision should focus on the following aspects.

\section{ESTABLISHING MORE GENERAL SUPERVISION SYSTEM BASED ON THE TRADITION}

The open education system is characterized by personal meeting of teachers and students. Teaching management combines the students, school and teachers together and seeks common development. The problems that how to strengthen the examination evaluation of students' online learning and discussion, examine the teachers' online teaching quality and answering questions on the Internet timely and effectively, check and adjust the validity and scientificity of distance teaching management are the new requirements for supervision. The traditional supervision is a valuable asset in open education and is worth keeping and developing because of its perfect system, efficient mode of operation and strict supervision program, which improve the quality of teaching, help teachers develop and accumulate rich experience. With the advance of times, teaching techniques are updated and the methods of remote supervision of teaching also need to keep pace with the times and get imbued with new elements. The effects of distance teaching quality have inevitable connection with teaching support. The scientificity of teaching management, the reasonability of teaching environment and the progressiveness of teaching equipment have direct impacts on 
the quality of teaching. Therefore, the innovation of teaching supervision should not be limited to the major and subject ones, but rather combine with the teaching equipment, technical environment, distance learning environment of students, the real-time and non-real time monitoring process of the teaching and learning closely, to expand the scope of supervision, undertake the supervision of the positive relevant factors and minor factors which influence the quality of teaching through the whole process, thus build up a general supervision system which is fully adapted to the modern open distance education's characteristics of supervising teaching, learning and management.

\section{UNDERTAKING MULTILEVEL TEACHING SUPERVISION BASED} ON REALITY

Open education with its unique modernization and convenience of educational approaches makes the teaching rapidly develop. However, teaching management and monitoring appears relatively weak situation. Teachers' tutoring, question answering, discussion and practice sometimes are mere resting on form. Students' homework and discussion are often copied from the network for the purpose of dealing with inspection and the effects of natural learning cannot be guaranteed. Therefore, constructing teaching supervision system of multi-levels should be more scientific and reasonable. However, this work in most areas has not implemented. Institution is set up, but the arrangement and implementation of tasks cannot be fulfilled with no actual effects. Supervision is constrained by the assignment of leaders, special inspection and report, but the essence of supervision is to actively serve teaching and students. we should take the teacher as the leadership, the student as the main body, learning-centered idea as the philosophy of open education to achieve the cultivation of innovative ability and practical ability as the goal, focus on the core issues of education quality, implement in teaching practice and activities, develop education quality research, comb the problems, undertake timely feedback, promote the reform and improve the quality of teaching. Only by promoting multi-level supervision can the professional development of teachers and occupation be provided with powerful supports.

The provincial teaching evaluation and supervision office is responsible for the national open universities. It should supplement supervision with guidance, inspect work, feedback problem and put forward rectification opinions for the whole province; it should guide the school supervision team to inspect teaching, put forward opinions and suggestions, provide consultation and decision support for the national open universities and their relevant departments. Specific approach are as followed: listening to reports, inspection of teaching point, questionnaire survey, personal interview, interview, accessing archives, online questionnaires, field supervision, online monitoring, online evaluation, online feedback, online rectification and network briefing.

Supervision group should supplement supervision with guidance and strengthen the service ideas of supervision throughout process. It is responsible for supervising, guiding and evaluating the school education, as well as data collection, summary and reporting. Open distance education supervision should fully embody the new concept of modern education technology which requires the supervision mechanism of each class to have a new mechanism connected the leadership with teachers. There should be not only the evaluation of manmachine environment, but also the remote learning environment as well as the whole process of learning and tutoring. This makes the supervision personnel expand supervisory view, strengthen awareness of team and enhance the supervision pattern with a full range of supervision concept so as to improve the teaching quality, serve teachers and technicians so that they could improve their professional levels, make students more efficient in learning. Supervision ways of teaching process are as followed:

\section{A. The real-time monitoring, evaluation and feedback, supervision and rectification of online teaching}

Despite the fact that teachers and students do not meet in personal under the mode of open education, teaching, lectures attendance and question answering are still the main means of teaching with the medium different from that of traditional forms, which increases the difficulties of teaching monitoring and management. Therefore, real-time monitoring, assessment and feedback, supervision and rectification are still an important link to ensure the quality of education. Horizontal sampling and vertical sampling should be taken of the quality of video courses by supervisors. Timely rectification should be put forward according to students' feedback.

\section{B. The real-time monitoring, evaluation and feedback, supervision and rectification of online discussion}

In the open education, students use the method of distance learning which makes the learning convenient, but the process and the effect of learning complex to monitor and control. Online discussion not only reflects the students' learning process, but also reflects the state of students learning. Therefore, the real-time monitoring, evaluation and feedback, supervision and rectification are not only the content of teaching management, but also be an important link of supervision work. The supervisor should monitor individual discussion, group discussion and the discussion between teachers and students as well as propose rectification requirements according to the implementation situation.

\section{The real-time monitoring, evaluation and feedback, supervision and rectification of online replies}

The online reply is the way to realize the teachers' functions of solving doubts in open education, by which teachers' capacities of solving doubts, educational levels and sense of responsibility are reflected. The real-time monitoring, evaluation and feedback, supervision and rectification of online replies should be the primary approach of assessment and supervision by supervisors.

\section{The real-time monitoring, evaluation and feedback, supervision and rectification of formative assessment}

The formative assessment in teaching system of TV universities is a very effective teaching management which not only effectively guarantees the implementation of open education, but also enables teachers to adjust content and 
method of teaching according to the self-learning problems of students. However, in most aspects of practice, the effective teaching management becomes a mere formality. The supervisor should undertake real-time monitoring, evaluation and feedback, supervision and rectification of formative assessment of all teachers, to ensure students to complete the learning task step by step in a defined period of time and complete their studies by themselves in real.

\section{TO REALIZE THE IDEAL AND HELP DEVELOP TEACHERS BASED ON PEOPLE-ORIENTED CONCEPTS}

In the relatively elastic and flexible work condition, college teachers have relative freedom of working, so some people regard teaching as the job done out of conscience", and that's why excellent teachers who make painstaking efforts are highly praised and respected. However, in the time of improving the cultural quality of the whole nation, the efforts of only several excellent teachers are far from enough. Only all the educators devote to teaching whole-heartedly can the ideal of teaching be fully achieved. The excellent distance open education attributes to the sense of occupational accomplishment. In order to guide and help teachers get adapted to the development of open education, keep up with the pace of development of international distance education, supervision must be continuous innovated.

In 1980 USA evaluation expert Cuba and Lincoln proposed that evaluation is to endow the objects evaluated with the value, which in essence a kind of psychological construction". This theory is regarded as the fourth generation of evaluation theory, which emphasizes the response and negotiation as the important symbols of evaluation. Evaluation is a process of the reconstruction of reality and creation by stakeholders. This evaluation theory highlights the people-oriented management philosophy. Teaching supervision should take inspection as the process and guidance as the purpose, divert a favorable turn of events to their advantage. The supervisors should care and help the supervised team and teachers with sincerity and enthusiasm instead of being too much hypercritical and reproaching. Supervisors should discover acutely and encourage the summary and popularization of fresh approach and experience. They should strengthen the guidance for teachers and tackle negative factors and emotions via persuasion. Specific approaches of supervision are as followed:

\section{A. Teacher discussion}

The discussion system of teachers, network and technical personnel, teaching staff, students for different subjects should be established. Supervisors should listen to their opinions, know of new situations and problems in teaching, technical support and learning process, listen to their opinions and suggestions in the aspects of school teaching management and service, give feedback and supervise timely. Authorized by the management, supervisors should explain some problems directly on behalf of the university, play the role of coordination so as to let teachers have genial feeling toward them.

\section{B. The screening, analysis and feedback of materials}

We must do the collecting, screening, analysis and feedback of teaching inspection information and establish archives for all kinds of information. Concerning first-hand data information collected in the supervision process, we need to discard the dross and select the essential, discard the false and retain the true, analyze and judge from the outside to the inside, classify it scientifically, establish individual, departments, units and comprehensive supervision information database, provide reference for teachers' self-evaluation and education, provide the basis for the teachers' promotion, evaluation and appointment etc. At the same time, it offers the basis for college leaders' decision.

\section{Subject Teaching and Research}

Hold special teaching activities to promote teaching communication and improve the quality of education. The organization of outstanding teachers to participate in the "exchange of teaching experience", "public seminar" and "presentation of teaching design" and other activities would promote teachers' in-depth study on teaching, cultivate and inspire young teachers and improve teaching quality.

\section{The training of teaching skills}

Open education covers almost all fields of humanity and science. Most of teachers come from non-normal majors, who have enough professional knowledge, but lack education theory of especially modern distance open education and the system training of teaching methods. The supervision content should also be aimed at the guidance and training of non-normal majors teacher. We should focus on training of the open education theory, teaching mode, ways of organizing teaching, making multi-media courseware, carrying out practical work and online replies as well as standard of the centralized practice procedures.

\section{E. Special lectures}

Teaching supervision experts give seminars according to the common problems found in inspection, including both theory and vivid examples. Teachers can understand the basic requirements of the teaching theoretically, analyze and understand their own case, grasp the classroom teaching techniques, which can make the young teachers master teaching skills, accelerate the young teachers' occupational promotion as soon as possible.

\section{F. Teachers' development orientation}

Open education teachers are mostly part-time teachers. Teacher development center could provide development services according to the teaching evaluation of teachers, such as professional, comprehensive as well as systematic teaching resources, and one-to-one counseling, training, evaluation and help. The instruction, help and guidance should be undertaken in the textbook analysis, preparation, making teaching plan, teaching activities and research. Such process makes the teacher has a stronger sense of belonging and identity, help teachers' development, cultivate teacher's sense of 
occupational accomplishment, inspire more devotion and enthusiasm of the part-time faculty for TVU education.

\section{G. Master teacher workshop}

We should take teacher training project as the core to promote teacher' development. We should establish teaching team with master workshop as the core, develop characterized majors by relying on teaching group and achieve research accomplishments based on features majors. We should enable young teachers to receive direct guidance from master teacher in various tasks in workshop in order to help the promotion of young teachers.

\section{H. Online home}

We should establish "online home" which supports the teacher development on the supervision website, realize the abundant education resources and platform-sharing mechanism, promote teachers' teaching development studies with the credit system to achieve the wide business communication via platform.

\section{CONCLUSION}

The supervisory staff of open education should keep up with the pace of international modern distance education, actively explore new ideas of supervision, participate effectively in the teaching management and service, provide constructive opinions and suggestions for the school and teaching, continuously innovate supervisory way, strengthen the prospective of supervision, realize the idea of supplementing supervision with guidance, promote the growth of teachers in real and improve the quality of open education.

\section{REFERENCES}

[1] Zhang Minxuan. Response, Consultation and Co-construction[J]. Foreign Educational Materials. 1995.03,pp53.

[2] Chen Hongxiang. Discussion on Teaching Supervision of Higher Vocational Colleges[J]. Journal of Wuhan Communication Management Institute. 2003.4,pp52.

[3] Wu Youliang. Practice and Thoughts of Supervision Implementation[J]. Journal of Changshu College. 2002.6,pp93

[4] Guba, Egon. Lincoln, Yvonna. Fourth Generation Evaluation. Translated by Qinlin, Jiang Yanling [M]. China Renmin University Press. 2008,12.pp134.

[5] Shen Shaohui. Strrengthening Supervision and Promoting Teaching Quality. Journal of Shaanxi Normal University. 2003,S1.pp188.

[6] Yang Zhijian. Some Thoughts of Establishing National Open University[J]. Distance Education in China. 2011,5,pp16. 